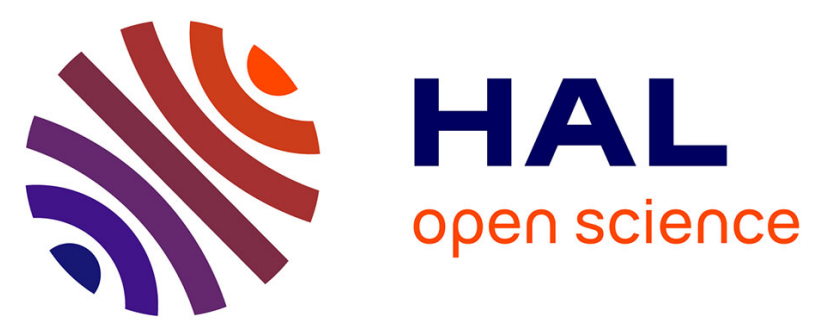

\title{
COPD is independently associated with 6-month survival in patients who have life support withheld in intensive care
}

\author{
Adel Maamar, Stéphanie Chevalier, Pierre Fillâtre, Vlad Botoc, Yves Le \\ Tulzo, Arnaud Gacouin, Jean-Marc Tadié
}

\section{To cite this version:}

Adel Maamar, Stéphanie Chevalier, Pierre Fillâtre, Vlad Botoc, Yves Le Tulzo, et al.. COPD is independently associated with 6-month survival in patients who have life support withheld in intensive care. The Clinical Respiratory Journal, 2018, 12 (7), pp.2249-2256. 10.1111/crj.12899 • hal-01807752v2

\section{HAL Id: hal-01807752}

https://hal-univ-rennes1.archives-ouvertes.fr/hal-01807752v2

Submitted on 14 Sep 2018

HAL is a multi-disciplinary open access archive for the deposit and dissemination of scientific research documents, whether they are published or not. The documents may come from teaching and research institutions in France or abroad, or from public or private research centers.
L'archive ouverte pluridisciplinaire HAL, est destinée au dépôt et à la diffusion de documents scientifiques de niveau recherche, publiés ou non, émanant des établissements d'enseignement et de recherche français ou étrangers, des laboratoires publics ou privés. 
COPD is independently associated with six-month survival in patients who have life support withheld in intensive care.

Maamar $\mathrm{A}^{1,2}$, Chevalier $\mathrm{S}^{3}$, Fillâtre $\mathrm{P}^{1,2,4}$, Botoc $\mathrm{V}^{3}$, Le Tulzo $\mathrm{Y}^{1,2,4}$, Gacouin $\mathrm{A}^{1,2,4}$, Tadié $\mathrm{JM}^{1,2,4}$.

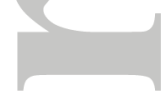

${ }^{1}$ Corresponding author: Service de maladies infectieuses et réanimation médicale, hôpital Pontchaillou, université de Rennes 1, 2, rue Henri Le Guilloux, 35033 Rennes cedex 9, France. Electronic address: adel.maamar@chu-rennes.fr

Fax +33299284116

Phone +33299284321

${ }^{2}$ Faculté de Médecine, Université de Rennes 1, Rennes, France.

${ }^{3}$ Service de réanimation polyvalente, centre hospitalier de Saint-Malo, 1 Rue de la Marne, 35400 Saint-Malo, France.

${ }^{4}$ Faculté de Médecine, Université de Rennes 1, Unité INSERM CIC 1414, IFR 140, Rennes, France.

Author contributions:

AM conceptualized the study and participated in its design, data acquisition and analysis, literature research, and the drafting of the manuscript. SC participated in the literature research, data acquisition and analysis, and the drafting of the manuscript. AG participated in the literature research, data acquisition and analysis, revising of the article for important 
intellectual content and drafting of the manuscript. PF participated in data acquisition and analysis and the drafting of the manuscript. VB participated in data acquisition and analysis and the drafting of the manuscript. YLT participated in revising the article for important intellectual content and the drafting the manuscript. JMT conceptualized the study and participated in its design, data analysis, and the drafting and revising of the manuscript for important intellectual content. All authors read and approved the final manuscript.

\section{Conflicts of interest statement:}

On behalf of all authors, the corresponding author states that there are no conflicts of interest.

This study was partly presented at the annual congress of the French Intensive Care Society Réanimation 2016.

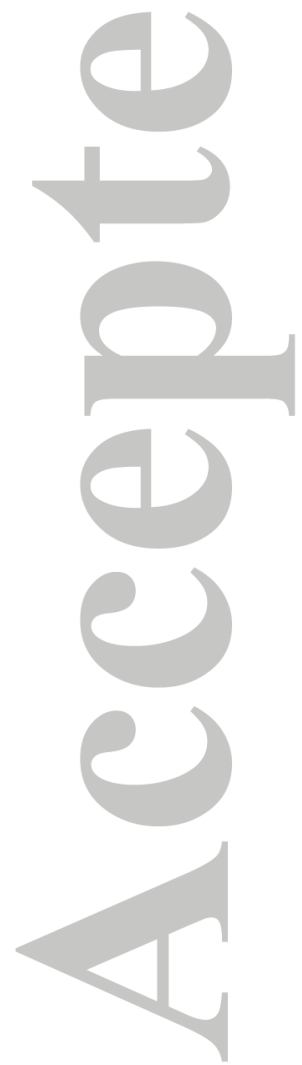




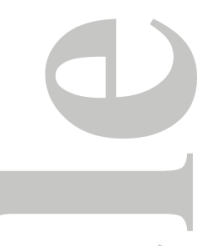

Abstract:

Background: In-hospital outcomes following decisions of withholding or withdrawing in Intensive Care Unit (ICU) patients have been previously assessed, little is known about outcomes after ICU and hospital discharge. Our objective was to report the six-month outcomes of discharged patients who had treatment limitations in a general ICU and to identify prognostic factors of survival.

Methods: We retrospectively collected the data of patients discharged from the ICU for whom life support was withheld from 2009 to 2011. We assessed the survival status of all patients at six months post-discharge and their duration of survival. Survivors and nonsurvivors were compared using univariate and multivariate analyses by Cox's proportional hazard model.

Results: One hundred fourteen patients were included. The survival rate at six months was $58.8 \%$. Survival was associated with acute respiratory failure (48\% vs. 19\%, $\mathrm{p}=0.006)$, a history of COPD ( $40 \%$ vs. $21 \%, p=0.03)$ and a lower SAPS II score (44 vs. $49, \mathrm{p}=0.006)$. We identified a history of COPD as a prognostic factor for survival in the multivariate analysis $(\mathrm{HR}=2.1 ; \mathrm{IC} 95 \% 1.02-4.36, \mathrm{p}=0.04)$.

Conclusion: A total of $58.8 \%$ of patients for whom life-sustaining therapies were withheld in the ICU survived for at least six months after discharge. Patients with COPD appeared to have a significantly higher survival rate. The decision to withhold life support in patients should not lead to a cessation of post-ICU care and to non-readmission of COPD patients. 
Keywords: Withholding treatment, prognosis, patients outcome, ethics, acute respiratory failure, COPD, critically ill patients.

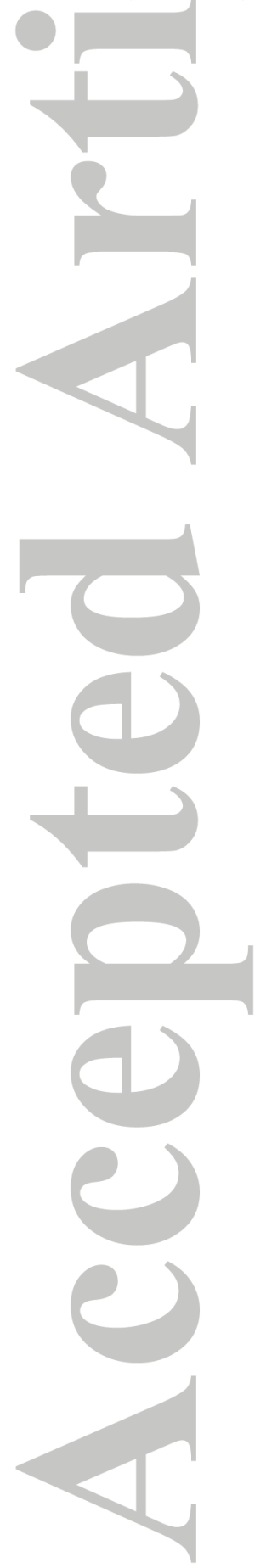




\section{Introduction:}

During the past 20 years, guidelines for the withholding (Wh) and withdrawal (Wd) of life support have been published in the United States ${ }^{1}$ and France ${ }^{2}$. In 2005, a law in France has been voted for $^{3}$ ( $n^{\circ} 2005-370$ of April 22, 2005), providing a legal framework for decisions to Wh or Wd life-sustaining treatments in critically ill patients. This law authorizes the withdrawal or withholding of life-sustaining therapies when they are "useless, disproportionate or have no other effect than solely the artificial preservation of life". It introduces the essential concept of futility and supports avoiding situations that may be considered as "irrational obstinacy".

Several studies have shown that the withholding and withdrawal of life support are common practices in Europe. For instance, Ferrand et $\mathrm{al}^{4}$ reported in 2001 that, in 113 French ICUs, $53 \%$ of ICU deaths were preceded by a decision to withhold or withdraw life support and that such decisions affected approximately $10 \%$ of all patients. These findings have been confirmed in more recent studies ${ }^{5-9}$ and it appears that the withholding of life support in critically-ill patients does not necessarily lead to death in the ICU. Ferrand et al. ${ }^{4}$ reported an ICU discharge rate of $43 \%$ after $\mathrm{Wh}$, and a recent study ${ }^{6}$ reported an ICU discharge rate of $37 \%$ and a hospital discharge rate of $17 \%$.

Although in-hospital outcomes in ICU patients following decisions to Wh or Wd life support have been previously assessed, the outcomes in these patients several months after hospital discharge remain unknown. For this purpose, we conducted a retrospective study to assess the six-month outcomes of patients discharged from the ICU after life-sustaining treatments were limited and to identify prognostic factors for survival. 


\section{Methods:}

\section{Study design and measurements:}

This study was conducted in a 15-bed ICU at the General Public Hospital of SaintMalo, France. All patients who had been discharged from the ICU and experienced withheld life-support from Jan 1, 2009 to Dec 31, 2011 were included in the study. Patients with incomplete data such as comorbidities or vital status at six months were excluded from the study.

Withholding was defined in accordance with the French guidelines ${ }^{2}$ edited by the French Intensive Care Society as a planned decision not to institute or optimize therapies that were otherwise warranted: endotracheal intubation, non-invasive ventilation, renal replacement therapy, increased doses of vasopressor infusions beyond a defined threshold, transfusion of blood products, antimicrobial therapy, surgery, increased fraction of inspired oxygen beyond a defined threshold, external cardiac massage, and ICU readmission. Data collected for all patients were as follows: age, sex, severity of illness at admission according to the simplified acute physiological score (SAPS II) ${ }^{10}$ and the sequential organ failure assessment score $(\mathrm{SOFA})^{11}$ at admission. Life expectancy was estimated using the McCabe classification ${ }^{12}$ : class A for no disease or a nonfatal underlying disease, class B for an ultimately fatal disease (death expected in a 5-year period), and class $\mathrm{C}$ for a rapidly fatal disease (death expected within 1 year). Diagnoses were coded according to the International Classification of Diseases, 10th revision (ICD-10). The primary diagnosis was defined according to the major organ dysfunction and classified into one of seven categories: acute respiratory failure without cardiac failure, coma including toxic causes, renal failure and metabolic disorders, acute pulmonary cardiogenic edema or shock, acute liver failure or digestive failure, surgical history, or sepsis ${ }^{13}$. We also recorded the following reasons for $\mathrm{Wd}$ or Wh based on items 
proposed by the French intensive care society: futility and/or poor expected quality of life, a severe underlying condition, or family or patient request $\mathrm{t}^{2}$. As the reason for $\mathrm{Wd}$ and $\mathrm{Wh}$ is required by French law, this item was systematically recorded in the medical records. Additionally, we recorded the involvement of the referring physician, ICU and in-hospital length of stay (LOS), and history of previous chronic diseases including chronic respiratory insufficiency, chronic obstructive pulmonary disease (COPD) according to the American Thoracic Society criteria ${ }^{14}$ (smoking, other environmental risk factors, chronic cough, acute chest illnesses, dyspnea, physical examination, and laboratory investigations such as chest radiography, lung function tests, or arterial blood gases); malignant disorders; class IV heart failure according to the New York Heart Association criteria; chronic neurological disease; proven cirrhosis; pre-existing renal insufficiency and severe psychiatric disorder (schizophrenia, major affective disorder, institutionalized or under protective supervision, such as tutorship and curatorship). We assessed the vital status at six months after ICU discharge for all patients by calling patients, their relatives, or their family doctor. If the patient was not alive, we recorded their length of survival. The primary aim was to assess the survival status at six months post-ICU discharge in patients with at least one treatment limitation. The secondary aim was to identify prognostic factors for six-month survival.

\section{Statistical analysis:}

Values are presented as the median (Inter Quartile Range) for continuous variables or number (percentages) for categorical variables. The two groups (survivors vs. non-survivors) were compared using Student's t-test for continuous variables and a chi-square or Fisher's exact test for categorical variables. First, univariate analysis was performed for each potential factor. Factors with a p value of less than 0.2 in the univariate analysis were then introduced 
as part of a Cox proportional hazard model, excluding redundant variables associated with long-term survival. Hazard ratios (HR) and their 95\% confidence intervals (CI) were estimated from the estimated parameters of the final regression model. Survival curves with a 95\% confidence interval were computed using the Kaplan-Meier method. Patients were censored at six months. Statistical analyses were performed using the StatView statistical software version 5.0 (SAS Institute, Cary, NC, USA); p values of less than 0.05 were considered significant.

\section{Ethical considerations:}

The study protocol was approved by the local ethical committee (15.108). Due to the nature of the study, patient informed consent was waived by the ethical committee.

\section{Results:}

\section{Overall Population:}

During the study period, 1483 patients were admitted to the ICU. The mortality rate was $17 \%$ (255 deaths, 1228 discharged from the ICU) during the ICU stay. Of the 1483 patients admitted, 264 had life support Wh or Wd during their ICU stay (17.8\% of all patients). Among them, 119 patients (45\% of this group and 9.7\% of all patients discharged from the ICU) were discharged from the ICU. Five patients were excluded because of incomplete data, specifically their comorbidities ( 2 patients) and their vital status at six months (3 foreign patients). Thus, 114 patients were included in the study group. Figure 1 shows the flowchart of the selection of included study participants. All patients from whom life support was Wd died in the ICU (145 patients). 
Of the 1483 patients admitted, 1219 had no treatment limitations and 110 died within six months $(9 \%)$ after ICU discharge.

Studied population: patients discharged from the ICU after a decision to withhold lifesustaining therapies.

The baseline characteristics of the study group are shown in Table 1. The Wh measures implemented are shown in Table 2. A total of 328 measures were taken. The previous quality of life was the most frequently reported reason for Wh life support. Endotracheal intubation was the most frequently cited type of limitation (81 patients, $71 \%$ ). Of note, NIV was withheld in $5 \%$.

\section{Long-term survival analysis after ICU discharge:}

After ICU discharge, 67 patients for whom life-sustaining therapies were withheld were alive (58.8\%), and $47(41 \%)$ patients had died within 6 months.

For the study group, the mean survival time was $124 \pm 72$ days.

Characteristics of the patients in the survivor and non-survivor groups at six months posthospital discharge are shown in Table 3. Survival was significantly associated with a longer length of ICU and hospital stay, an ICU admission for acute respiratory failure, a medical history of chronic respiratory disease or chronic obstructive pulmonary disease, and a lower SAPS II score at admission. To assess the impact of life expectancy before ICU admission, we compared the Mc Cabe score of patients according to each main comorbidity (Table 4). 
The multivariate analysis identified a previous history of COPD (HR=2.11; IC 95\% 1.02 4.36) and a longer length of hospital stay ( $\mathrm{HR}=1.03$; IC 95\% 1.004-1.5) as factors associated with better survival rates (Table 3 ).

\section{Long-term outcomes of COPD patients after ICU discharge for whom life-sustaining therapies were withheld:}

Forty-one patients were admitted for acute respiratory failure. The mean survival duration of these patients was 144 days versus 95 days for patients with other diagnoses. Eleven of these 41 patients $(26.8 \%)$ had been previously admitted to the ICU, and life support was withheld (no intubation) in the previous stays of 4 patients. We compared the survival rate of patients by previous history of COPD. As shown in Figure 2, the survival rate at 6 months postdischarge was significantly higher for patients with a previous history of COPD. Among the 37 patients with COPD, 11 (29\%) underwent invasive mechanical ventilation and 1 died. The remaining 26 COPD patients $(71 \%)$ received non-invasive ventilation and 9 died within 6 months. There was no significant difference in the survival rates of patients who did or did not receive invasive ventilation $(\mathrm{p}=0.11)$.

\section{Discussion:}

The results of our study showed that more than half of patients for whom life support was withheld in the ICU survived for at least 6 months after discharge. Among these patients with Wh decision, we also found that COPD patients had a significantly higher survival rate at 6 months post-discharge than did non-COPD patients.

Withholding life-supporting therapies does not predict certain death in the ICU. In our study, $45 \%$ of patients for whom life support was withheld in the ICU were discharged. In 
accordance with the findings of previous studies, we found that half of the deaths in the ICU occurred after the decisions to withhold or withdraw life support ${ }^{4,6-8}$. Among those patients for whom life support was withheld, $58.8 \%$ were still alive six months post-discharge. Lautrette et al. ${ }^{15}$ found in 2015 a Day-30 survival of $25 \%$ after withholding life-sustaining treatment. This difference may have 2 explanations. First, they distinguished patients with withholding and with no-escalation of life-sustaining therapies for whom Day-30 survival was $65 \%$. Second, the population of patients with chronic respiratory insufficiency was lower. Additionally, another recent French study found an ICU discharge rate of 37\% and a hospital discharge rate of $17 \%{ }^{6}$. These authors ${ }^{6}$ reported that withholding (not withdrawing) lifesupport therapies was associated with a mortality rate of only $56 \%$ after ICU discharge as we found in our study. Of note, the six-month survival of these patients was not assessed, however these results highlight the important survival difference between $\mathrm{Wh}$ and $\mathrm{Wd}$, as all authors report that survival rate of Wd patients is almost nil.

In our study, we found that the survival rate in these patients was significantly higher in patients with a previous history of COPD. COPD patients having survived an acute hypercapnic respiratory failure have a poor prognosis as they are highly susceptible to readmissions, life-threatening events, and death ${ }^{16}$, with or without Wh of life-sustaining therapies. Despite this poor prognosis, it seems better in our study than for other patients. This finding may have several explanations. First, we believe that this result arises from a better management of these patients in the COPD-treating ward, thus improving their prognosis during the post-ICU period. The death rate of COPD patients tends to stabilize ${ }^{17}$, probably because of a better management of $\mathrm{COPD}^{18}$ and an increased availability of hospital and home-based non-invasive ventilation $(\mathrm{NIV})^{19}$. It has been shown recently that home based NIV improves the survival of COPD patients, even among severe, stable patients ${ }^{20}$. This 
improvement was previously shown in patients with chronic respiratory failure secondary to neuromuscular or chest wall disorders ${ }^{21}$. A retrospective study suggested that long-term NIV could reduce the rates of hospital readmissions and acute hypercapnic respiratory failure in severe unstable COPD patients ${ }^{22}$. A recent multicentric randomized clinical trial of patients with persistent hypercapnia and hypoxemia showed that adding noninvasive ventilation to home oxygen therapy prolonged the time to readmission or death within 12 months ${ }^{23}$. Unlike other life support therapies that are only available in the ICU (such as vasopressor infusion), NIV is the only organ support therapy that is available daily at the same intensity at home, in the ward and in the ICU. Azoulay et al. showed that hospital mortality rates for COPD patients admitted for acute respiratory failure were lower in comparison with other patients in both do-not-intubate group and no treatment limitation group ${ }^{24}$. They also showed that there was no significant decline in their quality of life at day- 90 , and that $56 \%$ of patients with a donot-intubate status were alive at hospital discharge.

Second, according to recent studies, invasive mechanical ventilation worsens the short- and long-term prognoses of patients with acute-on-chronic respiratory insufficiency ${ }^{25,26}$. It also has been shown to be of no benefit in the most severe patients ${ }^{27,28}$. As endotracheal intubation was the most frequent life-support therapies withheld, we hypothesize that the COPD patients who had withheld life-support therapy during their ICU stay still benefited from NIV in ward and ICU during the following acute hypercapnic respiratory failure.

Of note, although other studies used day-30 or day-90 mortality, we decided to study 6 months mortality because of the high mortality rate expected and to avoid loss to follow-up

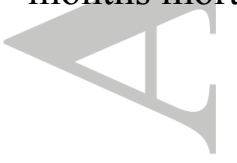

Our study highlights the importance of individualization of post-ICU follow-up care to improve patient survival and to avoid new exacerbations. Furthermore, we think that the 
decision to withhold life-support should not lead to not readmit these patients and should not refrain from treating the COPD patients for whom life-support was withheld.

We also found in our study that the survivor patients had a significantly longer hospital stay after ICU discharge probably due to a better general condition at discharge.In addition to the retrospective nature of the study, some limitations should be acknowledged. First, we can't exclude uncontrolled confounders or case-mix. Second, this is a single-center study, thereby limiting its external validity. Furthermore, we only considered COPD patients in our study since its represent the major etiology of chronic respiratory disease in our studied population. However, other chronic respiratory diseases such as idiopathic pulmonary fibrosis should be evaluated. Third, management of patients after ICU discharge should has been assessed, especially in COPD patients for whom home noninvasive ventilation prolonged the time to readmission or death within 12 months after an acute exacerbation ${ }^{23}$. Fourth, we can't exclude confounding factors that have not been assessed in this specific population such as sources of stress which could be responsible for early readmission ${ }^{29}$. Lastly, we do not have quality of life data for surviving patients, which would have been interesting. Recent studies have emphasized that the quality of life of critically-ill survivor patients was impaired when compared to that of the general population ${ }^{30}$, especially after septic shock ${ }^{31}$, and that improving quality of life following ICU discharge is an important issue.

\section{Conclusion:}

In conclusion, our study found that a substantial proportion of patients discharged from the ICU after life-sustaining therapies were withheld survived for at least six months. Among them, patients with COPD appeared to have a significantly higher survival rate. These results highlight the notion that the decision to withhold life-sustaining therapies should not lead to a cessation of post-ICU follow-up care and that COPD patients with a decision to withhold endotracheal intubation may still benefit of ICU-readmission. 


\section{References:}

1. Truog RD, Campbell ML, Curtis JR, et al. Recommendations for end-of-life care in the intensive care unit: a consensus statement by the American College [corrected] of Critical Care Medicine. Crit Care Med. 2008;36(3):953-963. doi:10.1097/CCM.0B013E3181659096.

2. Ferrand E, Société de Réanimation de Langue Française. End-of-life care in the intensive care unit. Recommendations of the Société de Réanimation de Langue Française. Rev Mal Respir. 2003;20(6 Pt 1):981-988.

3. LOI N 2005-370 Du 22 Avril 2005 Relative Aux Droits Des Malades et à La Fin de Vie.; 2005 .

4. Ferrand E, Robert R, Ingrand P, Lemaire F, French LATAREA Group. Withholding and withdrawal of life support in intensive-care units in France: a prospective survey. French LATAREA Group. Lancet. 2001;357(9249):9-14.

5. Esteban A, Gordo F, Solsona JF, et al. Withdrawing and withholding life support in the intensive care unit: a Spanish prospective multi-centre observational study. Intensive Care Med. 2001;27(11):1744-1749. doi:10.1007/s00134-001-1111-7.

6. Lesieur O, Leloup M, Gonzalez F, Mamzer M-F, EPILAT study group. Withholding or withdrawal of treatment under French rules: a study performed in 43 intensive care units. Ann Intensive Care. 2015;5(1):56. doi:10.1186/s13613-015-0056-x.

7. Orban J-C, Walrave Y, Mongardon N, et al. Causes and Characteristics of Death in Intensive Care Units: A Prospective Multicenter Study. Anesthesiology. 2017;126(5):882-889. doi:10.1097/ALN.0000000000001612.

8. Azoulay E, Metnitz B, Sprung CL, et al. End-of-life practices in 282 intensive care units: data from the SAPS 3 database. Intensive Care Med. 2009;35(4):623-630. doi:10.1007/s00134-008-1310-6.

9. Sprung CL, Cohen SL, Sjokvist P, et al. End-of-life practices in European intensive care units: the Ethicus Study. JAMA J Am Med Assoc. 2003;290(6):790-797. doi:10.1001/jama.290.6.790.

10. Le Gall JR, Lemeshow S, Saulnier F. A new Simplified Acute Physiology Score (SAPS II) based on a European/North American multicenter study. JAMA J Am Med Assoc. 1993;270(24):2957-2963.

11. Vincent JL, de Mendonça A, Cantraine F, et al. Use of the SOFA score to assess the incidence of organ dysfunction/failure in intensive care units: results of a multicenter, prospective study. Working group on "sepsis-related problems" of the European Society of Intensive Care Medicine. Crit Care Med. 1998;26(11):1793-1800. 
12. McCabe WR, Jackson G. Gram-negative bacteremia: I. etiology and ecology. Arch Intern Med. 1962;110(6):847-855. doi:10.1001/archinte.1962.03620240029006.

13. Boumendil A, Maury E, Reinhard I, Luquel L, Offenstadt G, Guidet B. Prognosis of patients aged 80 years and over admitted in medical intensive care unit. Intensive Care Med. 2004;30(4):647-654. doi:10.1007/s00134-003-2150-z.

14. Standards for the diagnosis and care of patients with chronic obstructive pulmonary disease. American Thoracic Society. Am J Respir Crit Care Med. 1995;152(5 Pt 2):S77121.

15. Lautrette A, Garrouste-Orgeas M, Bertrand P-M, et al. Respective impact of no escalation of treatment, withholding and withdrawal of life-sustaining treatment on ICU patients' prognosis: a multicenter study of the Outcomerea Research Group. Intensive Care Med. 2015;41(10):1763-1772. doi:10.1007/s00134-015-3944-5.

16. Chu CM, Chan VL, Lin AWN, Wong IWY, Leung WS, Lai CKW. Readmission rates and life threatening events in COPD survivors treated with non-invasive ventilation for acute hypercapnic respiratory failure. Thorax. 2004;59(12):1020-1025. doi:10.1136/thx.2004.024307.

17. Fuhrman C, Jougla E, Nicolau J, Eilstein D, Delmas M-C. Deaths from chronic obstructive pulmonary disease in France, 1979-2002: a multiple cause analysis. Thorax. 2006;61(11):930-934. doi:10.1136/thx.2006.061267.

18. Rycroft CE, Heyes A, Lanza L, Becker K. Epidemiology of chronic obstructive pulmonary disease: a literature review. Int J Chron Obstruct Pulmon Dis. 2012;7:457494. doi:10.2147/COPD.S32330.

19. Plant PK, Owen JL, Parrott S, Elliott MW. Cost effectiveness of ward based noninvasive ventilation for acute exacerbations of chronic obstructive pulmonary disease: economic analysis of randomised controlled trial. BMJ. 2003;326(7396):956. doi:10.1136/bmj.326.7396.956.

20. Köhnlein T, Windisch W, Köhler D, et al. Non-invasive positive pressure ventilation for the treatment of severe stable chronic obstructive pulmonary disease: a prospective, multicentre, randomised, controlled clinical trial. Lancet Respir Med. July 2014. doi:10.1016/S2213-2600(14)70153-5.

21. Annane D, Orlikowski D, Chevret S, Chevrolet JC, Raphaël JC. Nocturnal mechanical ventilation for chronic hypoventilation in patients with neuromuscular and chest wall disorders. Cochrane Database Syst Rev. 2007;(4):CD001941. doi:10.1002/14651858.CD001941.pub2.

22. Ankjærgaard KL, Maibom SL, Wilcke JT. Long-term non-invasive ventilation reduces readmissions in COPD patients with two or more episodes of acute hypercapnic respiratory failure. Eur Clin Respir J. 2016;3:28303.

23. Murphy PB, Rehal S, Arbane G, et al. Effect of Home Noninvasive Ventilation With Oxygen Therapy vs Oxygen Therapy Alone on Hospital Readmission or Death After an Acute COPD Exacerbation: A Randomized Clinical Trial. JAMA. 2017;317(21):21772186. doi:10.1001/jama.2017.4451. 
24. Azoulay E, Kouatchet A, Jaber S, et al. Noninvasive mechanical ventilation in patients having declined tracheal intubation. Intensive Care Med. 2013;39(2):292-301. doi:10.1007/s00134-012-2746-2.

25. Gacouin A, Jouneau S, Letheulle J, et al. Trends in Prevalence and Prognosis in Subjects With Acute Chronic Respiratory Failure Treated With Noninvasive and/or Invasive Ventilation. Respir Care. 2015;60(2):210-218. doi:10.4187/respcare.03467.

26. Gacouin A, Leveiller G, Guy T, et al. Long term survival in chronic obstructive pulmonary disease after ventilation in intensive care. Rev Mal Respir. 2009;26(3):257265.

27. Good care of the dying patient. Council on Scientific Affairs, American Medical Association. JAMA. 1996;275(6):474-478.

28. Singer PA, Lowy FH. Rationing, patient preferences, and cost of care at the end of life. Arch Intern Med. 1992;152(3):478-480.

29. Edmondson D, Green P, Ye S, Halazun HJ, Davidson KW. Psychological stress and 30day all-cause hospital readmission in acute coronary syndrome patients: an observational cohort study. PloS One. 2014;9(3):e91477. doi:10.1371/journal.pone.0091477.

30. Angus DC, Carlet J, 2002 Brussels Roundtable Participants. Surviving intensive care: a report from the 2002 Brussels Roundtable. Intensive Care Med. 2003;29(3):368-377. doi:10.1007/s00134-002-1624-8.

31. Nesseler N, Defontaine A, Launey Y, Morcet J, Mallédant Y, Seguin P. Long-term mortality and quality of life after septic shock: a follow-up observational study. Intensive Care Med. 2013;39(5):881-888. doi:10.1007/s00134-013-2815-1. 


\section{Figure legends}

Figure 1:

Patients flowchart of the 5-year period study.

WhWd $=$ withhold or withdraw treatment, ICU $=$ Intensive Care Unit.

\section{Figure 2:}

Kaplan Meier survival curve after ICU discharge through Day 180 of patients who have life support withheld by previous history of COPD.

COPD $=$ Chronic Obstructive Pulmonary Disease

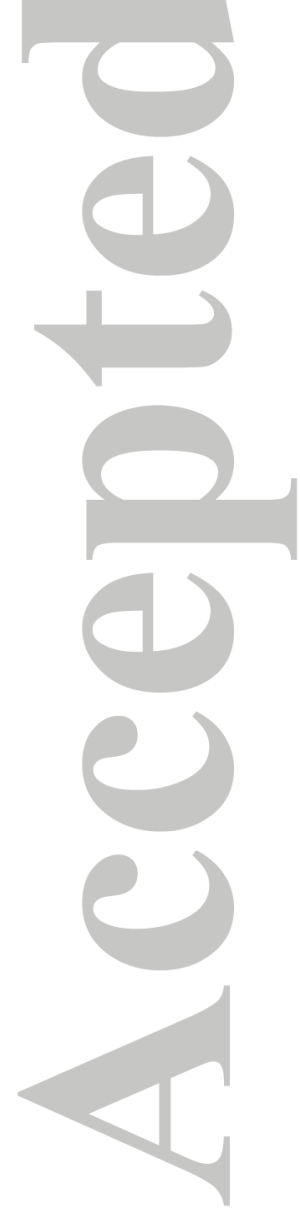


Table 1: General characteristics of patients discharged from the ICU withheld life-sustaining therapies.

\begin{tabular}{|c|c|c|}
\hline \multirow{2}{*}{ Age, years } & \multicolumn{2}{|c|}{$n=114$} \\
\hline & 78 & $\overline{(67-83)}$ \\
\hline Female gender & 66 & $(57.9)$ \\
\hline SAPS II, points & 45 & $(37-54)$ \\
\hline SOFA score, points & 4 & $(3-7)$ \\
\hline Length of ICU stay, days & 5 & $(3-9)$ \\
\hline Length of stay, days & 16 & $(8-32)$ \\
\hline \multicolumn{3}{|l|}{ Mc Cabe } \\
\hline A & 16 & (14) \\
\hline $\mathrm{B}$ & 68 & $(60)$ \\
\hline $\mathrm{C}$ & 30 & $(26)$ \\
\hline \multicolumn{3}{|l|}{ Main comorbidities } \\
\hline Number of comorbidities & 1 & $(1-2)$ \\
\hline Malignant disorder & 33 & $(30)$ \\
\hline Chronic respiratory insufficiency & 49 & (43) \\
\hline COPD & 37 & $(33)$ \\
\hline NYHA class IV heart failure & 44 & (39) \\
\hline Chronic neurological disease & 23 & $(20)$ \\
\hline Proven cirrhosis & 8 & (7) \\
\hline Pre-existing renal insufficiency & 13 & $(11)$ \\
\hline Severe psychiatric disorder & 12 & (11) \\
\hline \multicolumn{3}{|l|}{ Main indication for ICU } \\
\hline Acute respiratory failure & 41 & $(36)$ \\
\hline Coma including toxic causes & 23 & $(20)$ \\
\hline Acute heart failure or shock & 18 & $(16)$ \\
\hline Sepsis & 18 & $(16)$ \\
\hline Acute liver failure & 3 & (3) \\
\hline Renal failure and/or metabolic disorder & 6 & (5) \\
\hline Surgical & 5 & (4) \\
\hline \multicolumn{3}{|l|}{ Therapeutic outcomes } \\
\hline Vasopressors & 33 & (29) \\
\hline Mechanical ventilation & 42 & $(37)$ \\
\hline Dialysis & 9 & $(8)$ \\
\hline
\end{tabular}

Data are presented as number (\%) or median (interquartile range). Totals of main comorbidities are higher than $100 \%$ because several comorbidities were reported in most cases. SAPS = Simplified Acute Physiologic Score, SOFA = Sequential Organ Failure Assessment, ICU = Intensive Care Unit, COPD = Chronic obstructive pulmonary disease, NYHA = New York Heart Association. 
Table 2: Reasons given for withholding life-support therapies and their type.

\begin{tabular}{lll}
\hline Main Reason & $\mathrm{n}=114$ & $(\%)$ \\
Previous quality of life & 57 & $(50)$ \\
Futility or poor expected quality of life & 52 & $(46)$ \\
Family or patient request & 5 & $(4)$ \\
& & \\
Life-support therapy withheld & & \\
Endotracheal intubation & 81 & $(71)$ \\
Cardiopulmonary resuscitation & 59 & $(52)$ \\
Dialysis & 51 & $(45)$ \\
Non-ICU readmission & 47 & $(41)$ \\
Vasopressors & 43 & $(38)$ \\
Further surgery & 20 & $(18)$ \\
Tracheostomy & 20 & $(18)$ \\
Non-invasive ventilation & 6 & $(5)$ \\
Blood transfusions & 1 & $(1)$ \\
\hline
\end{tabular}

Data are numbers of patients (\%). Totals are higher than 100\%, because several reasons were given in most cases and several life-support therapies were withheld. ICU = Intensive Care Unit.

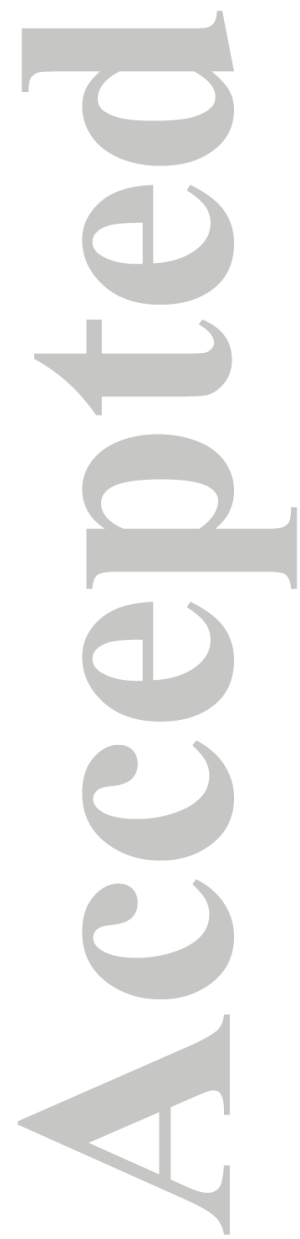


Table 3: Univariate and multivariate analyses for variables associated with six-month survival

\begin{tabular}{|c|c|c|c|c|c|c|}
\hline \multirow{2}{*}{ Variables } & \multicolumn{3}{|c|}{ Univariate analysis } & \multicolumn{3}{|c|}{ Multivariate analysis } \\
\hline & $\begin{array}{l}\text { Survivors } \\
(\mathrm{n}=67)\end{array}$ & Non-survivors $(\mathrm{n}=47)$ & $\mathrm{p}$ value & Hazard ratio & $95 \% \mathrm{CI}$ & $\mathrm{p}$ value \\
\hline Age, years & $78(65-83)$ & $78(68-83)$ & 0.76 & & & \\
\hline Female gender, $\mathrm{n}$ & $42(63)$ & $24(51)$ & 0.22 & & & \\
\hline SAPS II* & $44(36-51)$ & $49(41-59)$ & 0.006 & 0.69 & $0.38-1.27$ & 0.23 \\
\hline SOFA & $4(3-7)$ & $5(4-8)$ & 0.34 & & & \\
\hline ICU length of stay, days & $6(3-13)$ & $4(2-8)$ & 0.01 & & & \\
\hline In-hospital length of stay, days & $18(9-42)$ & $13(7-25)$ & 0.01 & 1.03 & $1.004-1.5$ & 0.01 \\
\hline Mc Cabe & & & 0.72 & & & \\
\hline $\mathrm{A} O$ & $9(13)$ & $7(15)$ & & & & \\
\hline B & $42(63)$ & $26(55)$ & & & & \\
\hline $\mathrm{C}$ & $16(24)$ & $14(24)$ & & & & \\
\hline SOFA at discharge from ICU & $2(2-4)$ & $2(2-4)$ & 0.63 & & & \\
\hline \multicolumn{7}{|l|}{ Main comorbidities } \\
\hline Number of comorbidities & $2(2-3)$ & $2(2-3)$ & 0.84 & & & \\
\hline Malignant disorders & $16(24)$ & $17(36)$ & 0.15 & 0.99 & $0.53-1.89$ & 0.96 \\
\hline COPD & $27(40)$ & $10(21)$ & 0.03 & 2.11 & $1.02-4.36$ & 0.04 \\
\hline Other chronic respiratory insufficiency $\dagger$ & $8(12)$ & $4(9)$ & 0.45 & & & \\
\hline NYHA class IV heart failure & $25(37)$ & $19(40)$ & 0.74 & & & \\
\hline Chronic neurological disease & $15(22)$ & $8(17)$ & 0.48 & & & \\
\hline Proven cirrhosis & $3(5)$ & $5(11)$ & 0.27 & & & \\
\hline Pre-existing renal insufficiency & $4(6)$ & $9(20)$ & 0.04 & 0.57 & $0.27-1.22$ & 0.15 \\
\hline Severe psychiatric disorder & $10(15)$ & $2(4)$ & 0.12 & 3.42 & $0.82-14.2$ & 0.09 \\
\hline \multicolumn{7}{|l|}{ Main indication for ICU } \\
\hline Acute respiratory failure & $32(48)$ & $9(19)$ & 0.006 & & & \\
\hline Coma including toxic causes & $11(16)$ & $12(26)$ & 0.23 & & & \\
\hline Acute heart failure or shock & $10(15)$ & $8(17)$ & 0.76 & & & \\
\hline Sepsis & $7(10)$ & $11(23)$ & 0.06 & & & \\
\hline Acute liver or digestive failure & $1(2)$ & $2(4)$ & 0.57 & & & \\
\hline Renal failure and/or metabolic disorder & $3(5)$ & $3(6)$ & 0.65 & & & \\
\hline Surgical & $4(6)$ & $1(2)$ & 0.65 & & & \\
\hline Collegial decision & $53(79)$ & $39(83)$ & 0.61 & & & \\
\hline Referring physician involved & $30(45)$ & $15(32)$ & 0.17 & 1.49 & $0.8-2.77$ & 0.21 \\
\hline
\end{tabular}

Data are presented as number (\%) or median (interquartile range). SAPS II = Simplified Acute Physiologic Score, SOFA = Sequential Organ Assessment Failure, ICU = Intensive Care Unit, COPD = Chronic obstructive pulmonary disease, NYHA = New York Heart Association, $\mathrm{MV}=$ Mechanical Ventilation. * Multivariate analysis compared SAPS II $>45 . \dagger$ Other chronic respiratory insufficiency were as follows: idiopathic pulmonary fibrosis, $n=3$, obesity and obstructive sleep apnea, $n=3$, bronchiectasis, $n=2$, myopathy, $n=2$, amyotrophic lateral sclerosis, $\mathrm{n}=2$.

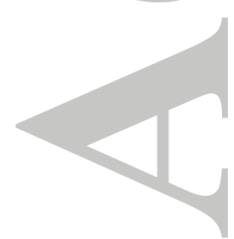


Table 4: Patients Mc Cabe score according to their comorbidities

\begin{tabular}{lllll}
\hline Variables & Mc Cabe A & Mc Cabe B & Mc Cabe C & p value \\
\hline COPD & $6(16)$ & $19(51)$ & $12(32)$ & 0.58 \\
NYHA class IV heart failure & $6(14)$ & $27(61)$ & $11(25)$ & 0.71 \\
Chronic neurological disease & $7(30)$ & $12(52)$ & $4(17)$ & 0.12 \\
Proven cirrhosis & $3(38)$ & $3(38)$ & $2(25)$ & 0.24 \\
Pre-existing renal insufficiency & 0 & $9(69)$ & $4(31)$ & 0.23 \\
Malignant disorders & $3(9)$ & $16(49)$ & $14(42)$ & 0.03 \\
Severe psychiatric disorder & $1(8)$ & $8(67)$ & $3(25)$ & 0.8 \\
\hline
\end{tabular}

Data are numbers of patients (\%). Totals are higher than 114 patients, because each patient can have several comorbidities. $\mathrm{COPD}=$ Chronic obstructive pulmonary disease, NYHA $=$ New York Heart Association. 


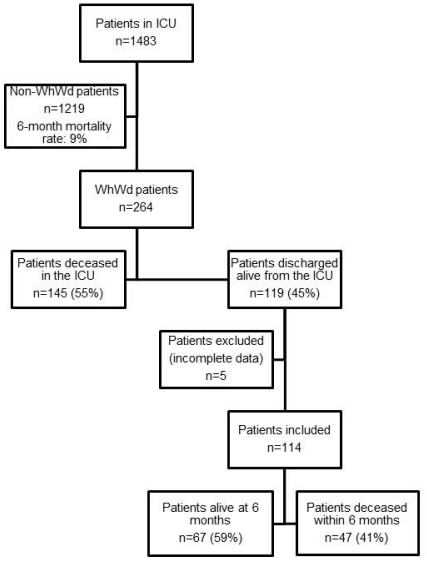




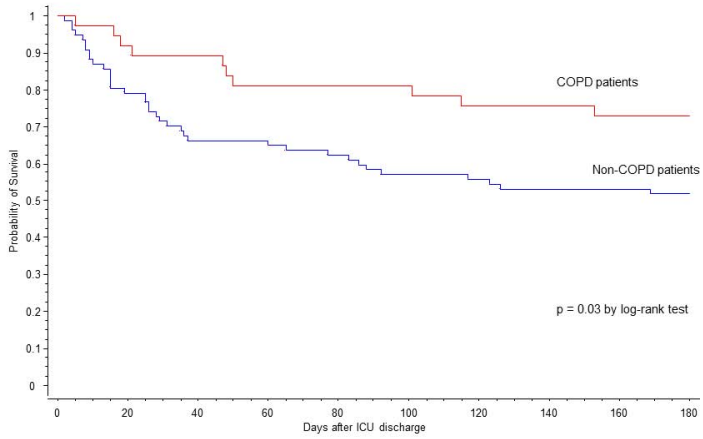

